\title{
Measurement of very Fast Transient over Voltages by using MATLAB in a 2-phase various Gas Insulated Substations
}

\author{
M. Kondalu \\ Electrical \& Electronics Engineering \\ Joginpally B.R. Engineering College, \\ Hyderabad
}

\author{
P.S. Subramanyam,Ph.D \\ Electrical \& Electronics Engineering \\ VBIT, Hyderabad
}

\begin{abstract}
This Paper deals with MATLAB circuits are develop to purpose for the components of various voltages of Gas Insulated Substations $(132 \mathrm{KV}, 220 \mathrm{KV}, 400 \mathrm{KV})$ and very fast transient over voltages are calculated by using the MATLAB software for single line to ground fault in a 3-phase system. Very fast transient over-voltage caused by disconnector switching off short bus is investigated in various gas insulated substations. The fast transients over voltages are caused due to switching operations and fault with Fixed resistance and Variable arc résistance. Measurement of very fast transient over voltages due to single line to ground fault in a 3-phase various gas insulated substations (132KV, 220KV, 400KV).
\end{abstract}

\section{Keywords}

3-phase system, Gas Insulated Substations (GIS), MATLAB software, VFTOs, Switching operations, Control circuitry.

\section{INTRODUCTION}

GIS is based on the Principle of Operation of complete enclosure of all energized or live parts in a metallic encapsulation, which shields them from the external environment. Compressed SF6 gas, which has excellent electrical insulating properties, is employed as the insulating medium between the encapsulation and the energized parts[1].

Gas Insulated Substations have a grounded outer sheath enclosing the high voltage inner conductor unlike conventional equipment whose closet is the earth surface. The Basic Insulation Level (BIL) required for a Gas Insulated Substations (GIS) is different from that of the conventional substation because of certain unique properties of the former Gas insulated bus has surge impedance $(70 \mathrm{Ohm})$ more than that of the conventional oil filled cables, but much less than that of an overhead line (300-400 Ohms)[2].

Gas Insulated Switchgears, also called Gas Insulated Substation, have been found a wide range of acceptance in power system for their compactness, high reliability and freedom from periodic maintenance etc. Running experiences have shown that switching operations of CB and DS within GIS will generate overvoltages, defined as Very Fast Transient Over-voltage (VFTO)[3], which has steep front and is followed by high frequency oscillations. Although the peak is n't too high, less than $2.5 \mathrm{pu}$, the accidents caused by VFTO are more than those caused by lighting impulse and switching overvoltage, especially at voltage levels higher than
$400 \mathrm{kV}$. The transformer is the main casualty of VFTO, the causes of which are as follows the voltage distribution along transformer winding is asymmetry and the turns in the head end withstand most of the voltage drop[4]. The other one is that the internal resonance over-voltage, which occurs when some of the VFTO frequency is equal to the natural frequency of the transformer, may overstress the winding insulation. The inner insulation of transformer has no selfrecovery capability, once damaged, it is difficult to repair, which cause a great loss to power system. Hence there is a need to estimate the magnitudes of VFTO at the transformer generated during different switching operations [5].

The authors first measured DS re-striking surges by selecting a $550 \mathrm{kV}$ GIS in actual operation. In effecting this in-field measurement, two methods were adopted-namely; (i) use of spacers existing in the GIS as potential dividers and use of optical fiber cables for signal transmission and (ii) simulation of re-striking by closing the low voltage mercury switch [6].

These measuring procedures were followed by calculations on the outcome with an attempt to make the calculated results coincide with the measured results. The authors shall introduce in this report their proposed GIS simulation methods in calculating DS re-striking surges [7]. They have conducted calculations regarding DS restriking surges on different DS locations in various types of GIS's; the resultant data has enabled us to estimate the magnitude variety of the DS re-striking surges at actual GIS's. In these calculations, employed was a digital program MATLAB[8].

\section{MODELING OF THE GAS INSULATED SUBSTATIONS $(132 \mathrm{KV}, 220 \mathrm{KV}, 400 \mathrm{KV})$}

The equivalent circuits are constructed by using MATLAB software. By using the circuits the transients are calculated for $10 \mathrm{mtrs}$ length of Gas insulated substations (132KV, 220KV, $400 \mathrm{KV})$. The transients are also calculated during single line to ground fault in 3-phase system.

The maximum magnitude of the transient over voltage is 2.0 p.u. This value is largely dependent upon the level of trapped charge on the GIS bus bar existing at the time of the re-strike. The amplitude of trapped charge is strongly influenced by the asymmetry of the intercontact break down Voltage occurring on the fixed and mobbing contacts of the dis-connector.

Under certain system configurations, the isolator switching operations could result in energizing or de-energizing a short section of GIS duct. Because of the relatively slow movement of the contacts 
of the isolator switches, pre-strikes or re-strikes would occur between the contacts, creating VFTO on the GIS, introducing a risk on the connected equipment, especially for transformer connected circuit. Due to its high frequency nature, the VFTO imposed on the transformers connected directly to the GIS would not be distributed evenly on all transformer windings. Some windings,

DS restriking surges that occur at GIS's differ depending on the GIS layout, installation positions of each DS, and circuit structure at the time of actual DS operation. However, discussions heretofore made in this report warrant the fact that the surge voltage of such extremely high frequencies can be estimated by means of calculations with excellent accuracy and reliability. Further, fortunately, or to make the matter more convenient, it was also confirmed that in simulating the gas-insulated duct lines or circuit breakers, strict simulation is not required on short branch lines of conductors, spacers, and differences between tank/conductor diameters. The findings the authors have thus obtained up to this point led them to proceed with another step of calculations of DS surges-namely, against the various operating DS installation positions in different commercial GIS's and varying circuit structures.

For these reason, VFTO generated in GIS should he considered as an important factor in the insulation design of not only gas insulated components, but the entire substation. The VFTO generated due to switching operation, breakdown may occur if any sharp protrusion exists within the GIS. The over voltage pattern may cause the VFTO break down. This type of breakdown is known as Secondary Breakdown. This type Breakdown is also possible at the switching contacts during the current interruption. From the insulation design point of view, this new VFTO level and amplitudes of the high frequency components are also important.

For designing a substation it is essential to know the maximum value of VFTO. Hence studies are carried out on estimation of the VFTO levels. For this purpose MATLAB software is used. In MATLAB software a suitable equivalent circuit is necessary for each component of the substation. From the above it can be seen that the estimation of magnitudes of VFTOs is essential for design of a GIS.These VFTO's are caused by switching operations and the single line to ground fault in a 3-phase Gas Insulated substations $(132 \mathrm{KV}, 220 \mathrm{KV}, 400 \mathrm{KV})$. Using MATLAB software of the equivalent models is developed.

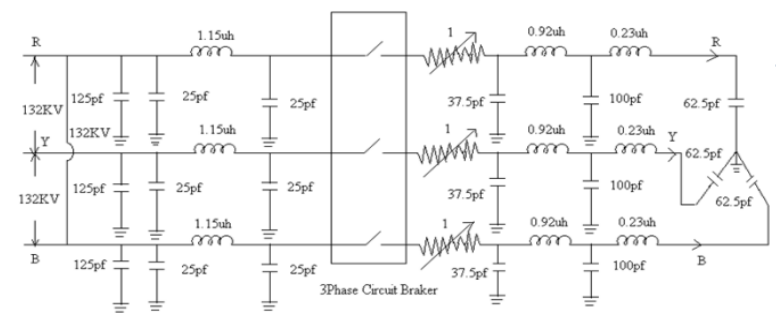

Fig1. Equivalent circuit for 10mtrs length during single line to ground fault in 3-phase $132 \mathrm{KV}$ GIS

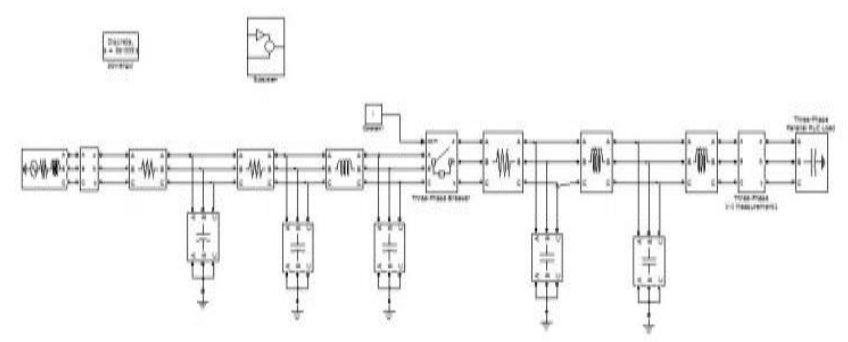

Fig 2 MATLAB circuit for 10mtrs length during single line to ground fault in 3 -phase $132 \mathrm{KV}$ GIS

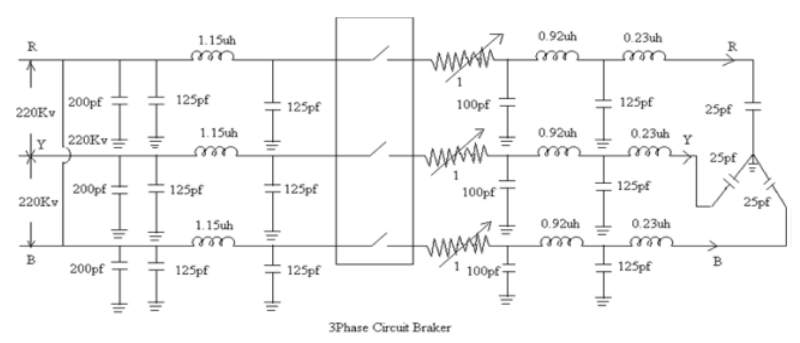

Fig 3. Equivalent circuit for 10mtrs length during single line ground fault in 3 -phase $220 \mathrm{KV}$ GIS.

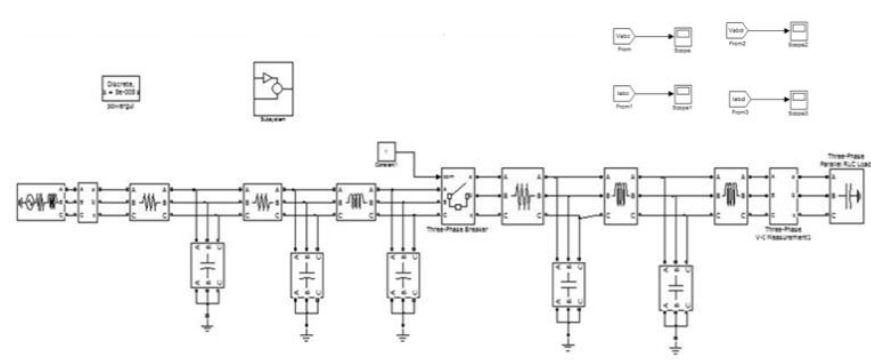

Fig 4. MATLAB circuit for $10 \mathrm{mtrs}$ length during single line to ground fault in 3 -phase $220 \mathrm{KV}$ GIS

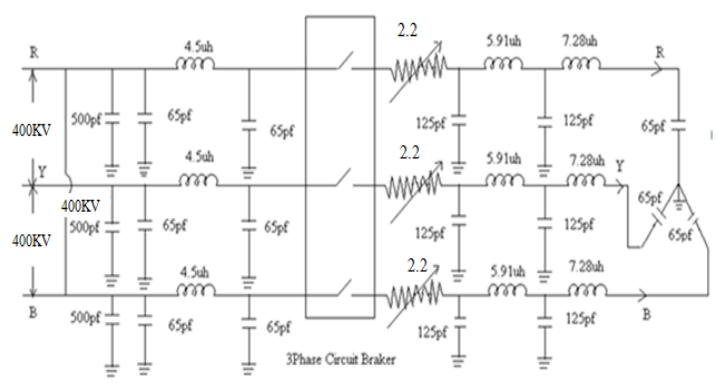

Fig 5. Equivalent circuit for 10mtrs length during single line ground fault in 3-phase 400KV GIS. 


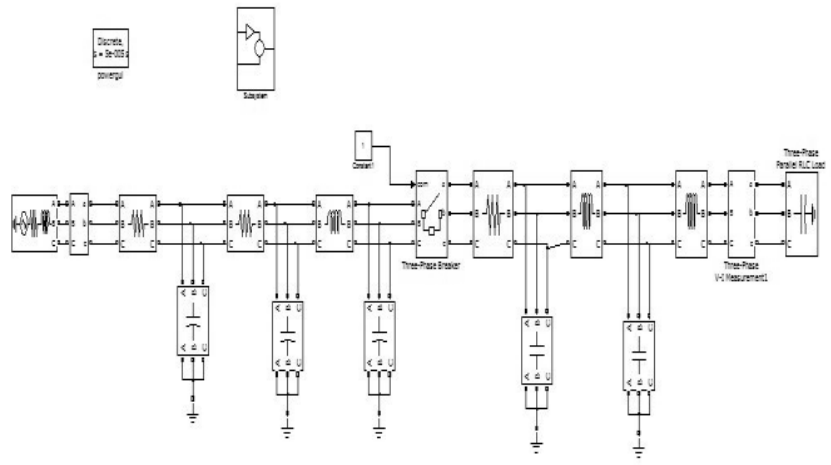

Fig 6. MATLAB circuit for 10mtrs length during single line to ground fault in 3 -phase $400 \mathrm{kV}$ GIS

\section{III.RESULTS AND DISCUSSION:}

The various transient voltage and current at different positions single line to ground fault in a 3-phase Gas insulated substations $(132 \mathrm{KV}, 220 \mathrm{KV}, 400 \mathrm{KV})$ for the first switching operation presented in results. The inductance of the bus bar is found out from the diameters of enclosure and conductors. The bus capacitance is calculated using formula for concentric cylinders. This circuit is divided into three sections of $1 \mathrm{mtrs}$, $4 \mathrm{mtrs}$ and $5 \mathrm{mtrs}$ respectively from load side and by the circuits shown in figures $1 \&$ 2 .are made use of. In a 3-phase circuit one phase (say phase B) has been earthed. This in effect makes the transmission line of 2-phases only. The MATLAB circuit of the same will be as shown in Fig 2.

The transients due to closing of the circuit breaker are calculated as shown in fig 7 . From this graph, the peak voltages obtained are 2.44 and 2.43p.u at rise times of 69 and $67 \mathrm{~ns}$ respectively. The magnitudes and rise times of 10mts length GIS are tabulated in the table 1.

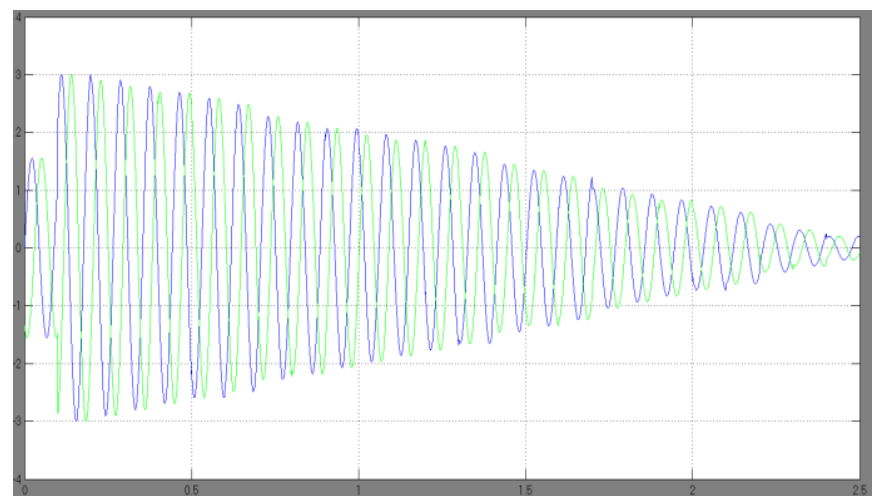

Fig 7 Transient voltage wave for MATLAB closing operation of CB for $10 \mathrm{mts}$ length in $132 \mathrm{kV}$ GIS

To introduce current chopping the circuit breaker is opened. The transients obtained during opening operation are shown in Fig 8. From the graph, the maximum voltages obtained are 1.24 and $1.23 \mathrm{p} . \mathrm{u}$ at rise times of 60 and $63 \mathrm{~ns}$ respectively. MATLAB circuit for $10 \mathrm{mtrs}$ length single line ground fault in a 3-phase $132 \mathrm{KV}$ GIS shown in the fig. The magnitudes and rise times of $10 \mathrm{mts}$ length GIS are tabulated in the table 1.

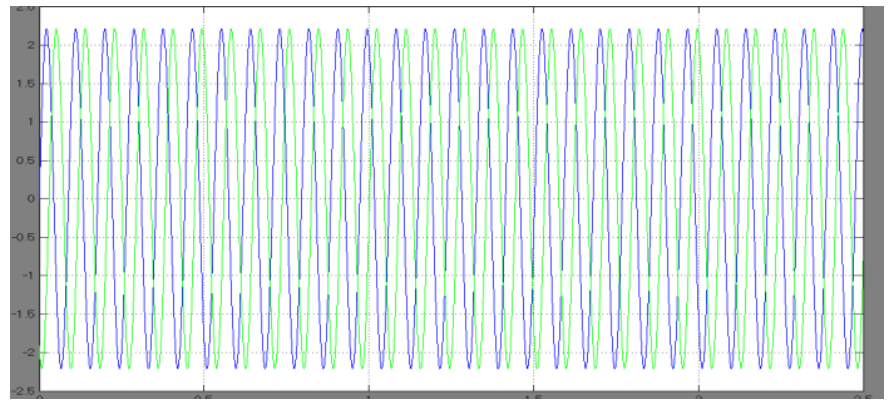

Fig8. Transient voltage waveform for MATLAB opening operation of $\mathrm{CB}$ for $10 \mathrm{mtrs}$ length in $132 \mathrm{kV}$ GIS.

Assuming a second re-strike occurs the transients are calculated by closing another switch at the time maximum voltage difference occurs across the circuit breaker. The transients obtained due to second re-strike are shown in Fig 9. From the graph, the maximum voltages obtained are 2.52 and 2.51 p.u at a rise times of 121 and $123 \mathrm{~ns}$ respectively. The magnitudes and rise times of $10 \mathrm{mts}$ length GIS are tabulated in the table 1.

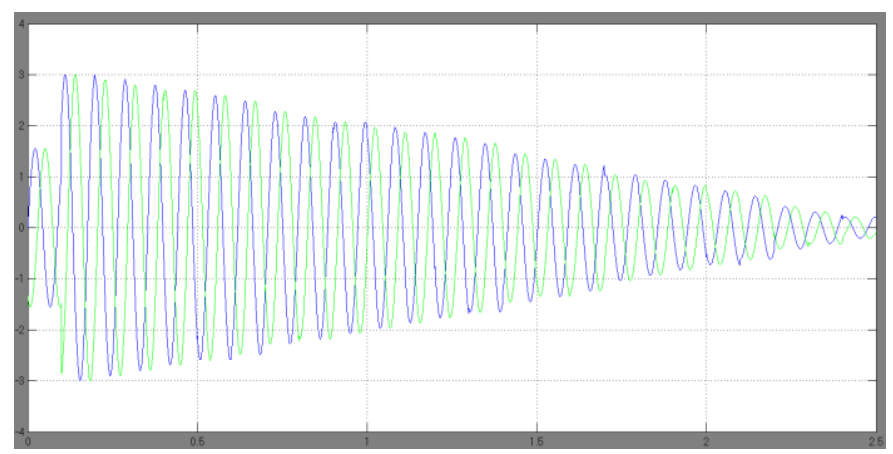

Fig9. Transient voltage waveform for MATLAB second Re-strikes for $10 \mathrm{mtrs}$ length in $132 \mathrm{kV}$ GIS

Table 1 Transient due to switching operations for 10mtrs length in a $220 \mathrm{KV}$

\begin{tabular}{|c|c|c|c|c|}
\hline \multirow{2}{*}{$\begin{array}{c}\text { Mode of } \\
\text { operation }\end{array}$} & \multicolumn{2}{|c|}{$\begin{array}{c}\text { Magnitude of } \\
\text { voltages(p.u) }\end{array}$} & \multicolumn{2}{|c|}{$\begin{array}{c}\text { Rise time } \\
\text { (Nano sec) }\end{array}$} \\
\cline { 2 - 5 } & $\begin{array}{c}\text { VR } \\
\text { phase }\end{array}$ & $\begin{array}{c}\text { VY } \\
\text { phase }\end{array}$ & tR & tY \\
\hline $\begin{array}{c}\text { During } \\
\text { closing } \\
\text { operation }\end{array}$ & 2.44 & 2.43 & 69 & 67 \\
\hline $\begin{array}{c}\text { During } \\
\text { opening } \\
\text { operation }\end{array}$ & 1.24 & 1.23 & 60 & 63 \\
\hline $\begin{array}{c}\text { During } \\
\text { second re- } \\
\text { strike }\end{array}$ & 2.52 & 2.51 & 121 & 123 \\
\hline \multicolumn{2}{|c|}{} & & & \\
\hline
\end{tabular}

This circuit is divided into three sections of $1 \mathrm{mtrs}, 4 \mathrm{mtrs}$ and $5 \mathrm{mtrs}$ respectively from load side and by the circuits shown in figures $3 \& 4$ are made use of. This in effect makes the transmission line of 2-phase only. The fast transients over voltages are generated 
not only due to switching operations but also due to 3-phase fault in 220KV GIS.

This circuit is divided into three sections of $1 \mathrm{mtr}$, $4 \mathrm{mtrs}$ and $5 \mathrm{mtrs}$ respectively from load side and by using the circuit shown below figure $3 \& 4$. In a 3-phase circuit one phase (say phase B) has been earthed. This in effect makes the transmission line of 2-phase only. The MATLAB circuit of the same will be as shown in Fig 4.

The transients due to closing of the circuit breaker are calculated as shown in fig 10. From this graph, the peak voltages obtained are 2.42 and $2.44 \mathrm{p} . \mathrm{u}$ at rise times of 67 and $68 \mathrm{~ns}$ respectively. The magnitudes and rise times of 10mts length GIS are tabulated in the table 2 .

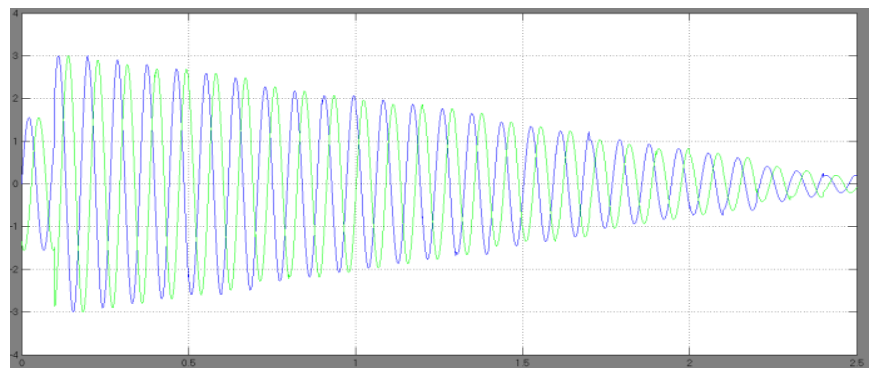

Fig 10.Transient voltage wave for MATLAB closing operation of $\mathrm{CB}$ for $10 \mathrm{mts}$ length in $220 \mathrm{KV}$ GIS.

To introduce current chopping the circuit breaker is opened. The transients obtained during opening operation are shown in Fig 11. From the graph, the maximum voltages obtained are 1.23 and $1.24 \mathrm{p} . \mathrm{u}$ at rise times of 63 and 62ns respectively. MATLAB Circuit for $10 \mathrm{mtrs}$ length in a 3 -phase to 2 -phase $220 \mathrm{KV}$ GIS shown in above fig4. The magnitudes and rise times of $10 \mathrm{mtrs}$ length GIS are tabulated in the table2. MATLAB Circuit for 10mtrs length during single line ground fault in a 3 -phase $220 \mathrm{KV}$ GIS shown in the fig 4.

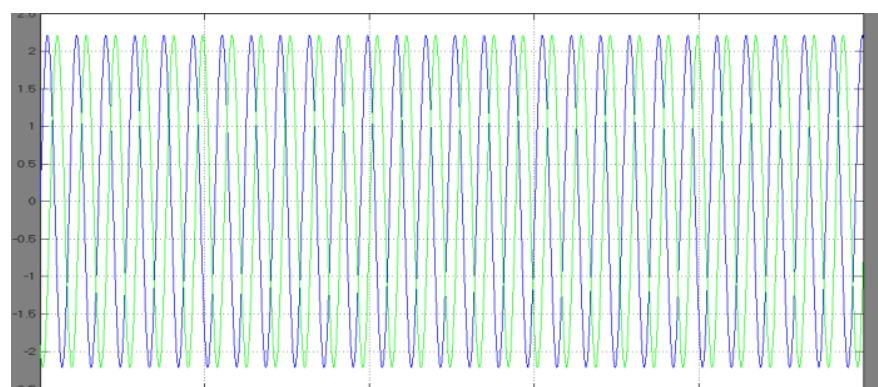

Fig.11. Transient voltage waveform for MATLAB opening operation of $\mathrm{CB}$ for $10 \mathrm{mtrs}$ length in $220 \mathrm{kV}$ GIS.

Assuming a second re-strike occurs the transients are calculated by closing another switch at the time maximum voltage difference occurs across the circuit breaker. The transients obtained due to second re-strike are shown in Fig 12. From the graph, the maximum voltages obtained are 2.52 and $2.51 \mathrm{p}$.u at a rise time of 123 and $122 \mathrm{~ns}$ respectively. The magnitudes and rise times of $10 \mathrm{mts}$ length GIS are tabulated in the table 2. The magnitudes and rise times of 10mts length GIS are tabulated in the table 2.

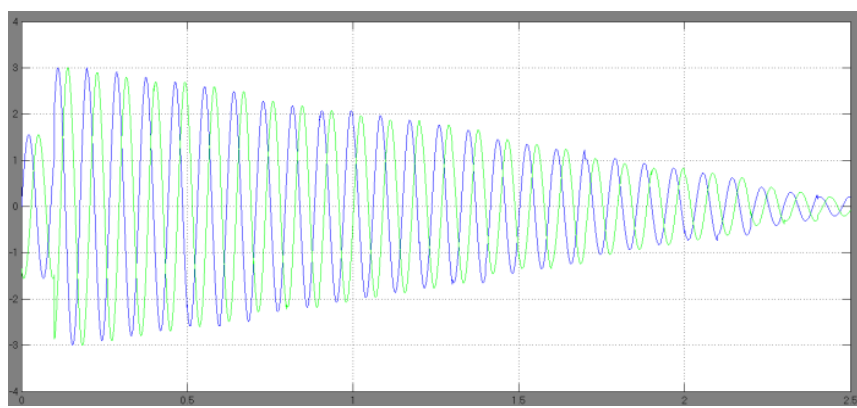

Fig 12 Transient voltage waveform for MATLAB second Re-strikes for $10 \mathrm{mtrs}$ length in $220 \mathrm{KV}$ GIS.

Table 2 Transient due to switching operations for 10mtrs length in $220 \mathrm{KV}$

\begin{tabular}{|c|c|c|c|c|}
\hline \multirow{2}{*}{$\begin{array}{c}\text { Mode of } \\
\text { operation }\end{array}$} & \multicolumn{2}{|c|}{$\begin{array}{c}\text { Magnitude of } \\
\text { voltages(p.u) }\end{array}$} & \multicolumn{2}{c|}{$\begin{array}{c}\text { Rise time } \\
\text { (Nano sec) }\end{array}$} \\
\cline { 2 - 5 } & $\begin{array}{c}\text { VR } \\
\text { phase }\end{array}$ & $\begin{array}{c}\text { VY } \\
\text { phase }\end{array}$ & tR & tR \\
\hline $\begin{array}{c}\text { During } \\
\text { closing } \\
\text { operation }\end{array}$ & 2.42 & 2.44 & 67 & 68 \\
\hline $\begin{array}{c}\text { During } \\
\text { opening } \\
\text { operation }\end{array}$ & 1.23 & 1.24 & 63 & 62 \\
\hline $\begin{array}{c}\text { During } \\
\text { second re- } \\
\text { strike }\end{array}$ & 2.52 & 2.51 & 123 & 122 \\
\hline
\end{tabular}

This circuit is divided into three sections of $1 \mathrm{mtr}$, $4 \mathrm{mtrs}$ and $5 \mathrm{mtrs}$ respectively from load side and by the circuit shown in figure $5 \& 6$ are made use of. In a 3-phase circuit one phase (say phase B) has been earthed. This in effect makes the transmission line of 2-phases only. The MATLAB circuit of the same will be as shown in Fig 6.

The transients due to closing of the circuit breaker are calculated as shown in fig 13. From this graph, the peak voltages obtained are 2.45 and $2.43 \mathrm{p} . \mathrm{u}$ at rise times of 72 and $71 \mathrm{~ns}$ respectively. The magnitudes and rise times of $10 \mathrm{mts}$ length GIS are tabulated in the table 3 .

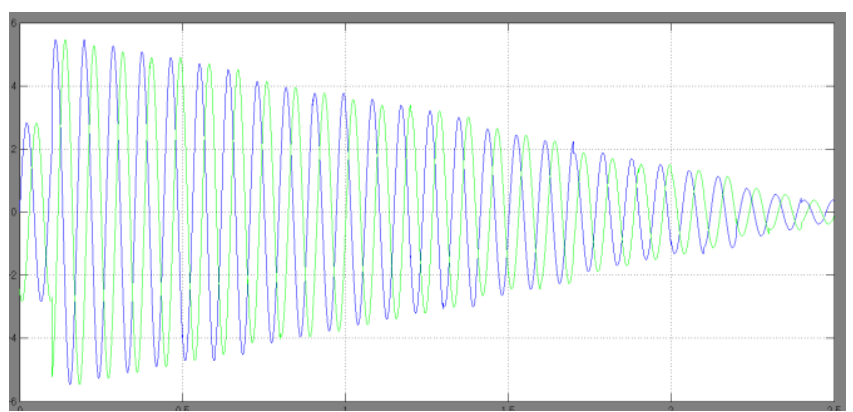

Fig 13. Transient voltage wave from for MATLAB closing operation of CB for 10mts length in 400KV GIS. 
Volume 72-No.9, May 2013

To introduce current chopping the circuit breaker is opened. The transients obtained during opening operation are shown in Fig 14. From the graph, the maximum voltages obtained are 1.23 and 1.22p.u. at rise times of 63 and62 ns respectively. MATLAB Circuit for $10 \mathrm{mtrs}$ length during single line to ground fault in 3-phase $400 \mathrm{KV}$ GIS shown in the fig 6 . The magnitudes and rise times of $10 \mathrm{mts}$ length GIS are tabulated in the table 3.

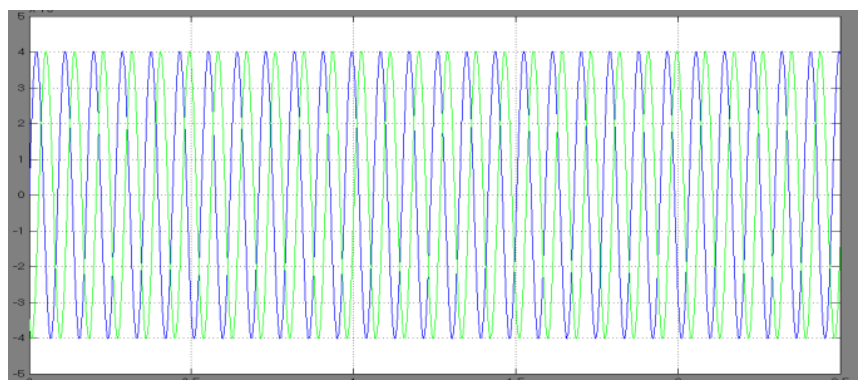

Fig. 14 Transient voltage waveform during opening operation of $\mathrm{CB}$ for $10 \mathrm{mts}$ length $400 \mathrm{kv}$ GIS

Assuming a second re-strike occurs the transients are calculated by closing another switch at the time maximum voltage difference occurs across the circuit breaker. The transients obtained due to second re-strike are shown in Fig 15. From the graph, the maximum voltages obtained is 2.52 and $2.53 \mathrm{p}$.u at arise time of 122 and $123 \mathrm{~ns}$ respectively. The magnitudes and rise times of $10 \mathrm{mts}$ length GIS are tabulated in the table 3 .

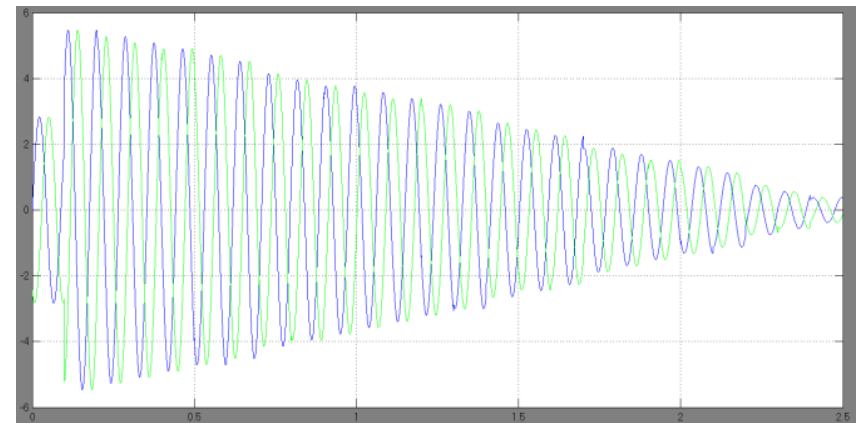

Fig.15. Transient voltage waveform from for MATLAB second re-strikes for $10 \mathrm{mts}$ length $400 \mathrm{kv}$ GIS

\section{Conclusion:}

The fast transient over voltages are obtained due to switching operation of single line to ground fault in 3-phase system are studied. The transients are calculated initially with fixed arc resistance and then variable arc resistance. The variable arc resistance is calculated by using Toepler's formulae. Transients along with load and without load are also calculated.

Transient voltages are also obtained for single line to ground fault $1 \mathrm{n} 3$-phase GIS systems for $220 \mathrm{KV} / 400 \mathrm{KV} / 132 \mathrm{KV}$ GIS due to switching operations using MATLAB software. Voltage waveforms are shown for 2-phase $220 \mathrm{KV} / 400 \mathrm{KV} / 132 \mathrm{KV}$ of GIS system for bus length of $10 \mathrm{mtrs}$, for opening and closing circuit breaker and re-strikes. Effect of variable Arc resistance on the magnitude of transient over voltages is also studied.
Table 3 Transient due to switching operations for $10 \mathrm{mtrs}$ length $400 \mathrm{KV}$

\begin{tabular}{|c|c|c|c|c|}
\hline \multirow{2}{*}{$\begin{array}{c}\text { Mode of } \\
\text { operation }\end{array}$} & \multicolumn{2}{|c|}{$\begin{array}{c}\text { Magnitude of } \\
\text { voltages(p.u) }\end{array}$} & \multicolumn{2}{c|}{$\begin{array}{c}\text { Rise time } \\
\text { (Nano sec) }\end{array}$} \\
\cline { 2 - 5 } & $\begin{array}{c}\text { VR } \\
\text { phase }\end{array}$ & $\begin{array}{c}\text { VY } \\
\text { phase }\end{array}$ & tr & ty \\
\hline $\begin{array}{c}\text { During } \\
\text { closing } \\
\text { operation }\end{array}$ & 2.45 & 2.43 & 72 & 71 \\
\hline $\begin{array}{c}\text { During } \\
\text { opening } \\
\text { operation }\end{array}$ & 1.23 & 1.22 & 63 & 62 \\
\hline $\begin{array}{c}\text { During } \\
\text { second re- } \\
\text { strike }\end{array}$ & 2.52 & 2.53 & 122 & 123 \\
\hline
\end{tabular}

\section{REFERENCES:}

[1] M.kondalu, G.Sreekanthreddy, Dr. P.S. subramanyam," Estimation of transient over voltages under various line fault conditions with respect to various gas insulated substations $(132 \mathrm{KV}, 220 \mathrm{KV}, 400 \mathrm{KV})$ published in $2^{\text {nd }}$ international conference on resent advances in science and Engineering april 29-30 2013

[2] M.kondalu, , Dr. P.S. subramanyam "Calculation of Transients at Different Distances in a single phase $220 \mathrm{kv}$ Gas Insulated substation published in International journal of Advanced Research in Computer Engineering \& Technology Issue4-Volume1 pages 28-33 - June-2012

[3] H. Hiesinger,RWitzmann. Very fast Transient Breakdown at a needle Shaped Protrusion, IX Int. Conf. on Gas Dis. and

Their [5] W. Boeck and W. Taschner, "Insulating Behavior of SF6 with and without Solid Insulation in Case of Fast Transients," CIGRE Paper No.1547, Aug. 1986. Transactions on Power Systems, vol. PWRD- 1, No. 2, pp. 95-101, 1983.

[4] R. Witzman, "Fast Transients in Gas Insulated Substations (GIS) - Modeling Of Different GIS Components," Fifth International 1987.

Symposium on High Voltage Engineering, No. 12.06,

[5] J. Lewis, B. M. Pryor, C. J. Jones, T. Irwin, "Disconnector Operations in Gas Insulated Substations Over voltage Studies

and Tests Associated with a $420 \mathrm{kV}$ Installation", CIGRE,Vol.

11,1988 , paper 33.09 , pages $1-8$

Appli. Sep 1988

[6] N. Fujimoto and S. A. Boggs, "Characteristics of GIS Disconnector-induced Short Rise time Transients Incident

on

87

Externally Connected Power System Components,'IEEE

185-2,New Orleans, Feb. 1987.
WM 
[7] M.kondalu, G.Sreekanthreddy, Dr. P.S. subramanyam,' Estimation Transient overvoltages in gas insulated bus duct from $220 \mathrm{kv}$ gas insulated substation", International journal of Computer applications, 2011.
[8] S. Nishiwaki, Y. Kanno, S. Sato, E. Haginomori, S. Yamashita, and S. Yanabu, "Ground Fault by Re-striking Surge of SF6 Gas insulated Disconnecting Switch and Its Synthetic Tests," Transactions on Power Apparatus and Systems, vol. PAS-102,No. 1, pp. 219-227, 1983. 